\title{
Patterns and processes in the drift of early developmental stages of fish in rivers: a review
}

\author{
Aaron Lechner • Hubert Keckeis • \\ Paul Humphries
}

Received: 6 November 2015/ Accepted: 23 May 2016/Published online: 7 June 2016

(C) The Author(s) 2016. This article is published with open access at Springerlink.com

\begin{abstract}
Current-mediated downstream dispersal by the early developmental stages of fish in rivers is a common phenomenon. Knowledge of patterns and processes in the dispersal, or 'drift', of young fishes provides important information on spawning location and spawning success, habitat use, movement paths and flow-ecology relationships more generally, all of which are critical for effective river conservation and management. But despite the importance of such information, our understanding of the patterns and processes of the drift of the early life stages of riverine fishes is limited. Furthermore, riverine fish drift research has tended to occur in isolation from movement studies of other organisms, limiting its integration with higher level concepts and theory. This manuscript reviews the literature on the dispersal of young fishes in running waters. Relevant studies from all climatic zones and geographical regions are investigated, with particular attention given to the
\end{abstract}

Electronic supplementary material The online version of this article (doi:10.1007/s11160-016-9437-y) contains supplementary material, which is available to authorized users.

A. Lechner $(\bowtie) \cdot$ H. Keckeis

Department of Limnology and Oceanography, Faculty of Life Sciences, University of Vienna, Althanstrasse 14, 1090 Vienna, Austria

e-mail: aaron.lechner@univie.ac.at

P. Humphries

School of Environmental Sciences, Charles Sturt

University, PO Box 789, Albury, NSW 2640, Australia types and life history stages of fishes that drift and the seasonal and diel patterns of drifting. We then consider how fish enter the drift and their mode of drifting, attempting to reconcile a long-running discussion, under what we call the active-passive conundrum'. We argue that, aside from eggs, the early stages of fish are not exclusively either passive or active drifters, but usually a mixture of the two, which we term 'actipassive' drift. Finally, we evaluate existing knowledge in the context of a general conceptual framework for movement ecology, identifying gaps in our understanding of the roles of internal state, navigation capacity, motion capacity, external factors and internal factors in influencing the dispersal process.

Keywords Fish larvae - Free embryos - Drift . Dispersal · Rivers

\section{Introduction}

Placing a fine-mesh net in a river in spring or early summer will usually catch the eggs, free embryos and larvae of fishes moving downstream, sometimes in vast numbers. These early developmental stages of fishes are participating in the first mass movement of their lives, dispersing from spawning or nursery sites to what are presumed appropriate rearing habitats (Pavlov 1994). This group includes individuals that 
seem deliberately to use the current to help them move (Braaten et al. 2012), and others that are apparently accidentally entrained (Harvey 1987; Wolter and Sukhodolov 2008). Whatever the mechanism, current-mediated dispersal—or 'drift'—of the young stages of fish is an integral part of the life cycle of many riverine species (Muth and Schmulbach 1984; Bujold et al. 2004; Humphries 2005). It enhances habitat connectivity and gene flow, promotes community stability and extends the range of populations (Janac et al. 2013; Roberts et al. 2013).

While drifting, eggs, free embryos and larvae are relatively simple to collect, and these collections can provide much information on the dynamics of early life. This information can elucidate patterns and processes associated with spawning and larval production (Zitek et al. 2004a; King et al. 2005; Braaten et al. 2010; Borcherding et al. 2014), it may allow forecasting of future year-class-strength (Johnston et al. 1995) and provide estimates of stock size of spawning adults (Usvyatsov et al. 2013). It also assists in understanding how fishes and their environmentespecially the flow environment-interact. This is vital for effective river management, because the presence of drifting fishes provides evidence of in situ reproduction of native and alien species, common and rare species, and species important for recreational and commercial fisheries (Humphries and Lake 2000; Jiang et al. 2010).

This sort of information is also critical if we are to assess, and perhaps counter, the impact of flow alteration and other anthropogenic disturbances (Pavlov et al. 2008; Bracken and Lucas 2013; Lechner et al. 2014a). But despite the importance of such information, our understanding of the patterns and processes of the drift of the free embryos and larvae of riverine fishes is limited (Corbett and Powles 1986; Flecker et al. 1991; Schmutz and Jungwirth 1999). There are many studies from around the world that have described temporal and spatial patterns of drift of the larvae of riverine fishes (e.g. Gadomski and Barfoot 1998; Oesmann 2003; Zitek et al. 2004b). These include a range of temporal scales, from diel, daily to seasonal (e.g. de Graaf et al. 1999; Copp et al. 2002; Araujo-Lima and Oliveira 1998). But what catalyses fish larvae to drift in the first place, how far they drift, how they navigate to settlement sites, how they detect these sites, how they exit the current, how they avoid predation and other hazards en route, and how significant this dispersal is to population dynamics, are largely unknown (but see Johnston 1997; Robinson et al. 1998; Schludermann et al. 2012).

Here we review the literature on the patterns and processes associated with the dispersal of the free embryos larvae and juveniles of riverine fishes, with the overall aim of understanding why, how and where fish drift and how drifting fish interact with the riverine environment. We searched a range of scientific databases (Google Scholar, Web of Science, Scopus) and employed the search terms fish larvae + drift + dispersal + rivers.

The review is divided into three sections. In the first, we consider species-, stage-and location-specific characteristics of fish drift, and discuss drift patterns at different temporal scales. In the second section, we highlight processes associated with the downstream movement of young fish; i.e. the entry into the current and the subsequent behaviour in the flow. We discuss established classifications and introduce new approaches based upon recent insights. In the third section, the existing literature on fish drift is analysed in the context of the unifying organismal movement model of Nathan et al. (2008), by evaluating the state of knowledge relating to the internal state, motion capacity and navigation capacity of drifting fish. Knowledge gaps are identified and suggestions for future research, towards an integrated approach in drift studies, are made.

\section{What types of fishes drift?}

The intensity of drift, its governing mechanisms and the importance of the process in the life cycle of fishes is species-specific (Johnston et al. 1995; D'Amours et al. 2001). For example, Reichard et al. (2001) discriminated between taxa that continuously appeared in the flow of a Czech lowland river and others that were exclusively found during elevated discharge. Humphries and King (2004) classified species based on the relevance of drift to their life history. Species were categorized as obligate- (high abundance in drift, low abundance in other habitats), facultative- (occur in similar abundance in the drift and in low-flow habitats) or non-drifters (low abundance in the drift, drift entrance is likely accidental). The assignation to a specific group appears independent of velocity preference of the adults of particular 
species: some normally limnophilic species as adults (e.g. Rhodeus sericeus, Cyprinidae) drift as larvae and utilize the flow for dispersal (Jurajda 1998), whereas the larvae of some normally rheophilic species as adults (e.g. Squalius cephalus, Gobio spp., Cyprinidae) avoid drifting (Brown and Armstrong 1985; Reichard et al. 2001).

Species-specific patterns in initial drifting patterns greatly depend on the spawning mode of the fish in question (Pavlov 1994). Pelagophilous fish release buoyant or semi-buoyant eggs that immediately enter the flow and, apart from the influence of buoyancy and shape, drift passively (Araujo-Lima and Oliveira 1998; Jiang et al. 2010; Widmer et al. 2012). Embryos and larvae successively develop in the water column during transport (Wootton 1998). By contrast, the early embryogenesis of salmonids (brood hiders) and many rheophilous cyprinids (open-substrate spawners) is characterized by an extended below-gravel period (Persat and Olivier 1995; Bardonnet 2001). Here, the first dispersers are free embryos or welldeveloped larvae that enter the current after the yolk sac is depleted. The influence of the spawning mode on subsequent drift events weakens as the fish grow and develop specific phenotypes and behaviours, resulting in variable drift patterns within the same reproductive guild (Pavlov 1994).

Other factors affecting patterns of drift are related to the migratory behaviour of the adults. In some amphidromous species, for example, larval drift is a continuous downstream movement, with a distinct spatial goal: the ocean (Iguchi and Mizuno 1990; Maeda and Tachihara 2010). Movement between freshwater and the sea is, in this case, an obligate part of the life history, and so it is unsurprising that drift is deliberate and controlled (Bell and Brown 1995). Wholly freshwater fishes, however, tend to show more diverse drift patterns (Pavlov et al. 1978). For example, whereas larvae of the anadromous smelt (Osmerus eperlanus, Osmeridae) use strong currents in the mid-channel of the River Elbe as a vehicle for swift downstream movements, potamodromous cyprinids instead drift in moderate currents along the shoreline (Oesmann 2003). Likewise, while larvae of some amphidromous sculpins (Cottus aleuticus, Cottus asper, Cottidae) in Smith and Van Duzen rivers, Northern California, expedite their dispersal to estuaries by drifting at elevated river flows, the potamodromous fish community here apparently has evolved life histories that minimize the risk of transport into saltwater (White and Harvey 2003).

However, comprehensive drift models for potamodromous fish are, with a few exceptions, largely absent or theoretical. Apparently, the larvae of long migratory, potamodromous sturgeon species feature a continuous drift over several days and hundreds of kilometres (see Online Resource). Drift distance and duration are highly variable among species, and may be genetically coded in order to reach distinct nursery habitats and to compensate for the long upstream migrations of the adults (D'Amours et al. 2001; Kynard and Horgan 2002; Kynard et al. 2007a, 2007b; Braaten et al. 2008, 2012). Instead of a continuous downstream movement, the early dispersal of other potamodromous species potentially includes a sequence of drifting phases (primarily during night), interspersed with periods of inshore settlement in nursery habitats (primarily during day) (Carter et al. 1986; Gadomski and Barfoot 1998). The cumulative distance covered during this pattern is not known and needs more research.

\section{At what life history stage do fishes drift?}

Drifting typically occurs during defined intervals of ontogeny and at certain body lengths for particular species. A narrow size range of drifting individuals, for example, has been observed in two invasive benthic species (Neogobius melanostomus, Proterorhinus semilunaris, Gobiidae) in the River Dyje, Czech Republic (Janac et al. 2013), catfish alevins (Ictalurus punctatus, Pylodictus olivaris, Ictaluridae) in the Illinois River, Arkansas (Brown and Armstrong 1985), and particular native fishes (Catostomus latipinnis, Catostomus discobolus, Catostomidae; Gila robusta, Rhinichthys osculus, Cyprinidae) in the Colorado River, Colorado (Carter et al. 1986). The Murray cod (Maccullochella peelii, Percichthyidae) in the Murray River, Australia (Humphries 2005), and pumpkinseeds (Lepomis gibbosus, Centrarchidae) in the River Rhone, France (Copp and Cellot 1988), predominantly drift as free embryos. Cyprinids, on the other hand, mostly disperse during their early larval development (larval stages L1-L4; Copp et al. 2002; Zitek et al. 2004a; Sonny et al. 2006) or at the transition between the larval and the juvenile period (stages 
L6/J1; Reichard and Jurajda 2007; Lechner et al. 2014b). But the former generality, that downstream dispersal is most intensive during early embryogenesis and sharply decreases upon the achieving of the juvenile period (Pavlov 1994), does not always apply: e.g., the drift in two Czech rivers, Morava and Kyjovka, and in a bypass section of the River Rhone was dominated by juvenile cyprinids, percids and cobitids (Peňáz et al. 1992; Reichard et al. 2001).

Drifting by fishes at particular sizes and developmental stages may be an adaptation to coping with, or taking advantage of, riverine conditions. Behavioural and physiological changes during development may enable certain stages to actively react to their environment and to temporally and spatially regulate their drift (Pavlov et al. 2008). Developmental stage, for instance, was found to correlate with change in swimming ability and habitat or diet shifts among seven drifting cyprinid species (Reichard and Jurajda 2007) and swimming ability of several MurrayDarling Basin fishes (Kopf et al. 2014). Alternatively, the size-structure of drifting cyprinids in the diel cycle might instead relate to an altered reaction to light during ontogeny. It may only be older, more-developed larvae that respond to the transition from day to night by moving into the current (Reichard et al. 2002a; Zitek et al. 2004b).

In fact, stage-specific drift patterns have also been observed in non-riverine species (Rhodeus sericeus, Cyprinidae; L. gibbosus, Centrarchidae) inhabiting running waters (Copp and Cellot 1988; Jurajda 1998), suggesting that stage-dependency could merely reflect susceptibility to entrainment in the current. Ontogenetic changes in morphology (i.e. filling of the swim bladder) and behaviour, as well as deficits (i.e. low visual acuity and swimming ability), or even improvements (i.e. enhanced swimming capacity and activity) in physical capabilities, may increase chance encounters with high currents, thereby inducing washouts and accidental drift (Harvey 1987; Persat and Olivier 1995). It must be borne in mind, however, that the stage and size distributions of larvae collected in a drift net may be an artefact of the spatial distribution of drifting larvae and how larvae are collected. For example, catch composition will be affected substantially by the spatial [e.g., distance from shore (Reichard et al. 2004), distance from hatching sites (Sonny et al. 2006) or vertical position in the water column (Pavlov et al. 1978)] and temporal [e.g., diel or seasonal (Carter and Reader 2000)] design of the sampling program or the used sampling gear (Tonkin et al. 2007).

\section{At what time of the year do fishes drift?}

The timing of drift is directly linked to that of reproduction (Brown and Armstrong 1985). The peak in spawning- and hence drift activity is presumably adaptive and initiated by environmental cues that promise favourable conditions for the progeny (Somarakis et al. 2000). The most important factors, in this respect, are water temperature (Carter et al. 1986; Johnston 1997; D'Amours et al. 2001; Reichard et al. 2002b; Hay et al. 2008) and discharge (Johnston et al. 1995; Robinson et al. 1998; Araujo-Lima and Oliveira 1998; Auer and Baker 2002). Either because fish do not spawn or produce viable eggs and larvae (i.e. reproductive effects; Zitek et al. 2004a) or because larvae do not survive (i.e. recruitment effects; Schiemer et al. 2001; Humphries et al. 2013), temperature and discharge not only govern the timing, but also the spawning success and hence the subsequent intensity of larval drift (Reichard et al. 2002b; Durham and Wilde 2008; Ellsworth et al. 2010b). Intra-and inter-annual variation in drift densities, for instance, may be attributed to fluctuations in water temperature and the related variability in egg mortality during incubation (Busch et al. 1975; Sonny et al. 2006). Rising discharge levels during certain periods may inundate breeding grounds, and ensure efficient oxygenation of the eggs, thereby increasing larval density and inducing seasonal drift peaks (Johnston et al. 1995; de Graaf et al. 1999; Martin and Paller 2008).

The time-density curves of larval drift are often location- or river-specific and can be informative about the composition of the resident fish assemblage (Humphries and Lake 2000; Reichard et al. 2002b). $\mathrm{Bi}$-and multi-modal seasonal patterns are characteristic of taxa-rich waters and reflect time-staggered spawning and drifting of species (Jiang et al. 2010). Additionally, multiple spawning events throughout the season of frequently drifting species may contribute to these patterns (Zitek et al. 2004b; Janac et al. 2013). Unimodal drift patterns can occur when single species dominate in the drift, or peak drift densities of 
different species overlap in the seasonal course (Lechner et al. 2014b).

\section{At what time of the day do fishes drift?}

The pronounced circadian rhythm of drift, with peak densities during the night, is a unifying pattern that applies for virtually all fishes and fish-like organisms. For example, drifting lamprey ammocoetes (superclass: Agnatha) show a nocturnal increase in abundance (Johnston 1997; White and Harvey 2003; Bracken and Lucas 2013), as do some sturgeon species (superclass: Gnathostomata, infraclass: Chondrostei) (D'Amours et al. 2001; Kynard and Parker 2006) and many teleost fishes (superclass: Gnathostomata, infraclass: Teleostei) (Johnson and McKenna 2007; Durham and Wilde 2008; Jiang et al. 2010). Daynight ratios of drifting fish vary between 1:1.3 (Peňáz et al. 1992) and 1:190 (Reichard et al. 2004). The diurnal differences in downstream dispersal are most likely related to the light level and its influence on drift entrance (see next section). Different species and ontogenetic stages of fish respond to different levels of light, apparently resulting in time-staggered density peaks of species (dusk, night and dawn; Pavlov et al. 1978; Brown and Armstrong 1985, Janac et al. 2013), and sizes of larvae throughout the course of the night (Zitek et al. 2004b; Sonny et al. 2006). Similarly, varying light conditions not only induce intra-specific differences in drifting patterns among rivers (Johnson and McKenna 2007), but also along the course of the same river (Iguchi and Mizuno 1991). Low illumination or water transparency during the day (e.g. high turbidity during flood events) can cause a cessation of diel periodicity in drifting (but see review by Reeves and Galat 2010). Nevertheless, the mechanisms driving diel patterns in drift are uncertain, and results far from unequivocal: for example, some drift studies have not detected temporal patterns (Muth and Schmulbach 1984; Robinson et al. 1998; Braaten et al. 2012; Borcherding et al. 2014) or the influence of water turbidity (Jurajda 1998).

\section{The active-passive-conundrum (APC)}

There has been a long-standing debate about the active or passive nature of fish drift (Pavlov 1994; Reichard and Jurajda 2004; Copp et al. 2002; Schludermann et al. 2012). Entry into the current and the subsequent downstream movement may be deliberate, with the ultimate aim of efficient dispersal. Presumably, this behaviour occurs in response to particular environmental cues, and evolved to expedite the process of downstream dispersal (Robinson et al. 1998; Lechner et al. 2014b). If this is the case, drift should be considered a predominantly active process. The alternative explanation is that drift primarily occurs accidentally, and environmental factors, such as current and light, override the physical capabilitiesswimming capacity and orientation —of small fish (Corbett and Powles 1986; Wolter and Sukhodolov 2008). In that case, drift should be considered a predominantly passive process.

In reality, knowledge about larval behaviour is still fragmentary (Reichard and Jurajda 2007; Pavlov et al. 2008), and many authors discuss both active and passive explanatory models; but typically they offer no resolution or integration (Gadomski and Barfoot 1998; Bardonnet 2001; Humphries and King 2004; Reichard et al. 2004; Sonny et al. 2006). An analysis of what we call the "Active-Passive-Conundrum" (APC), based on empirical studies, is outlined in the next sections. Specifically, we assess what we know about how fish larvae enter the drift and how they behave while drifting and contrast the internal and external factors involved. In our review, the work of Dmitry Pavlov is pivotal (Pavlov 1994, Pavlov et al. 1978, 1995, 2008, 2011). His concepts on the nature of fish drift are briefly summarized at the beginning of each of the following sections. We then offer a classification of drift entrance modes and suggest modifications to Pavlov́s model of active/passive drift, based upon our review of the drift literature.

\section{Drift entrance and its reasons}

According to Pavlov (1994), drift entrance incorporates mechanisms of different orders. First order mechanisms enhance fish activity and distribute them in the open water. They constitute the prerequisite for drift entrance, and include behavioural responses that either can be related (specific behavioural responses) or unrelated (non-specific responses) to the current (Pavlov et al. 2008). Second order mechanisms inhibit rheoreaction, the fish's inherent behaviour to move 
against a current (Pavlov 1994). In the following, we use Pavlov's work, substantiated by other significant research in the field, to introduce three scenarios for how young fish can enter the current.

Entry into the drift can be: (a) accidental, caused by environmental conditions that exceed and inhibit the individual's ability to maintain position, and flushes them away from nursery or hatching sites (passive drift entry); (b) partly behavioural, when unrelated factors (e.g., feeding movements, flight responses) cause young fish in the open water to be exposed to strong currents and they are entrained (coincidental drift entry); or (c) deliberate, as an adaption to fluvial conditions, and relying on innate species- and stagespecific behavioural responses that are aimed at leaving or reaching specific habitats (active drift entry). Discriminating between these alternative explanations is largely speculative. We can only guess at what initiates, and the ultimate goal of, drifting behaviour. And mechanisms may change during ontogeny for the same species, where the probability of a passive entry could decrease with increasing physical and behavioural abilities (Pavlov 1994; Kynard et al. 2007b). In the following, we consider each mode of drift entry in turn.

\section{Passive drift entry}

In passive drift entry, elimination of rheoreaction is triggered by the loss of visual cues at low illumination and in swift flows, or by the inability of fishes to resist overcritical current speeds (Pavlov 1994). In this respect, small fish are particularly vulnerable, because both swimming capacity and visual acuity increase with size, and are limited in embryos and larvae (Wanzenböck and Schiemer 1989; Flore et al. 2000).

The loss of visual orientation and the ensuing displacement from refuges is a common explanation for the increase in drift density of fish larvae with the onset of darkness and in highly turbid waters (Northcote 1962; Corbett and Powles 1986; Gadomski and Barfoot 1998; Peňáz et al. 1992; Reichard et al. 2001; Oesmann 2003; Reeves and Galat 2010). In this context, Bardonnet (1993) demonstrated that phosphorescent landmarks lessened the nocturnal drift peak of emerging brown trout (Salmo trutta, Salmonidae). Additionally, experiments by Pavlov et al. (1972) on various teleost species showed that the critical current velocities that young fish could resist were markedly higher in light than in darkness.

Other studies highlight the effect of high current velocities during flood events on influencing larvae to enter the drift (Reichard et al. 2001). The larvae of usually non-drifting species were frequently detected in the flow during rising water levels in two Australian rivers (Humphries and King 2004). The authors concluded that these individuals were flushed from backwaters and other still-water habitats. Harvey (1987) observed a taxon-and size-specific susceptibility of downstream displacement by flooding in Brier Creek, Oklahoma, where smaller fish $(5-10 \mathrm{~mm})$ were at greater risk of being entrained than larger ones (10-25 mm). Likewise, washouts of mainly eurytopic $0+$ cyprinids during a summer flood in the river Oder, Germany, caused a drastic decline in fish densities in different mesohabitats (Bischoff and Wolter 2001). Drifting during flood events can lead to substantial mortality, likely caused by gill damage from suspended sediment (Mion et al. 1998). Notably, moderate variation in discharge does not appear to affect the abundance or taxonomic and size composition of drifting larvae (Corbett and Powles 1986; Robinson et al. 1998; Copp et al. 2002; Reichard and Jurajda 2004; Zitek et al. 2004b; Humphries 2005).

\section{Coincidental drift entry}

Drift entry may be initiated by behaviours which are not targeted deliberately at dispersal, but expose young fish to strong currents (sensu non-specific behavioural responses; Pavlov et al. 2008). In that case, individuals inadvertently enter the flow while emerging from substrate, or during feeding activities and flight responses.

The directional movements of larvae in response to a light stimulus (=phototaxis) are considered crucial for the coincidental entrance of young fish into the water column (Pavlov 1994). Positive and negative photoreactions are species-specific, unconditioned reflexes to certain levels of illumination (Pavlov et al. 1978). They inter alia mediate the emergence of recently hatched larvae from the spawning substrate in order to fill the swim bladder and start exogenous feeding (Persat and Olivier 1995; Zitek et al. 2004b). Photoreactions are supposed to be important determinants of temporal drift patterns. Observations by Iguchi and Mizuno (1990), for example, indicate that 
diel drift patterns in the Japanese common goby (Rhinogobius brunneus, Gobiidae) depend on light preferences of the free embryos and changes in the ambient light conditions along a river course.

Armstrong and Brown (1983) and Brown and Armstrong (1985) concluded that coincidental drift entry relates to a higher risk of colliding with fast currents after initiation of feeding activities, because they detected only a few pro-larvae (with yolk sac), and mainly uniform-sized post-larvae (without yolk $\mathrm{sac}$ ), in the Illinois River. Encounter rates with currents can also increase during exploratory behaviour and may depend on visual habitat heterogeneity. For example, in experiments with Cichlasoma octofasciatum, Cichlidae, Pavlov et al. (2008) discovered that motor activity during habituation in novel surroundings is higher when visual landmarks are missing.

\section{Active drift entry}

Young fish commonly leave a specific area in order to escape unfavourable conditions or to reach the most advantageous habitats. Active drift entry, together with the utilization of the river current as means of transport, may have evolved to facilitate these movements (Gadomski and Barfoot 1998; Ellsworth et al. 2010a; Braaten et al. 2012). There are several reasons for relocations during early life-history. One of the most important may be the matching of larval requirements and environmental conditions at certain points of ontogeny. Mismatches in these two can arise immediately after hatching, when vulnerable embryos and early larvae face the swift-flowing, nutrient-poor spawning grounds chosen by their parents (Bardonnet 2001; Keckeis 2001). And they can occur later, when food or physico-chemical requirements change (Corbett and Powles 1986; Bardonnet 2001; Schiemer et al. 2003). Consequently, the initial drift entry at the spawning site, along with a rapid transport to suitable near-shore feeding areas and subsequent movements between these nurseries, are crucial for maximizing energy gain and survival (Jonsson 1991; Usvyatsov et al. 2013). By diluting the naturally high aggregation of individuals at spawning sites and nurseries, drift entry and dispersal also reduce the attraction of predators, the risk of cannibalism and competition for food and space (Copp et al. 2002; Humphries 2005). Population density effects, by way of example, are the main dispersal drivers in salmonid fry: downstream movement of territorial young brown trout (Salmo trutta, Salmonidae) ceased, independent of current speeds, after a constant final proportion of fish had been displaced (Daufresne et al. 2005). The smaller and lighter fry component of steelhead (Oncorrhynchus mykiss, Salmonidae) and Atlantic salmon (Salmon salar, Salmonidae) left their hatching sites, because they were out-competed by larger conspecifics in establishing and holding territories (Johnston 1997; Bujold et al. 2004; Johnson et al. 2013).

Although drift entry is often linked to illumination and current velocity, lack of correlation between these variables and abundance of drifting individuals may provide evidence for the deliberate nature of the process. For example, there was no relationship between light intensity and body length of drifting cyprinids in the River Morava (Reichard et al. 2002a). A negative correlation was expected if drift entrance was catastrophic and solely attributed to a sizedependent loss of visual orientation and neutralisation of rheoreaction. The conclusion that entry into the drift is a time-dependent behavioural decision is supported by other studies: Sonny et al. (2006) ascribed the observed differences in the diurnal size range of drifting chub (Squalius cephalus) and roach (Rutilus rutilus, Cyprinidae) in the River Meuse, Belgium, to diverging dispersal strategies of both species; Pavlov (1994) watched roach larvae actively entering the flow of a hydrodynamic channel during the night; in experiments with brown trout, Roussel and Bardonnet (1999) showed that upstream movements were predominantly nocturnal, indicating that darkness might instead of inhibiting a fish́s orientation, in fact allow it the freedom to disperse. Irrespective of why fish choose to enter the current, doing so during the night or at high levels of turbidity may be beneficial, and be a way of avoiding visual predators (Clark and Pearson 1980; Johnston 1997; Copp et al. 2002; Usvyatsov et al. 2013). Another hypothesis, that adaptive nighttime drift entrance of young fish corresponds to the feeding on synchronously drifting invertebrates (Elouard and Leveque 1977), is rather implausible: capture success and consumption rate of larvae sharply decrease with increasing velocity (Flore and Keckeis 1998) and decreasing light (Blaxter 1986), making it difficult for drifting fish to locate and eat prey. Most larvae are caught with empty guts at night (Shepherd and Mills 1996). 
Other results suggest that rising water levels and current speeds do not necessarily trigger a passive displacement, but an active movement of young fish. Increasing current speeds, during elevated discharge, neither affected abundance nor size and age of drifting young-of-the-year cyprinids (Reichard and Jurajda 2004). In a similar way to the effects of light, young fish may enter the drift only under particular hydraulic conditions (Johnston et al. 1995; Araujo-Lima and Oliveira 1998). Studies on Kootenai white sturgeon larvae (Acipenser transmontanus, Acipenseridae) in artificial streams concluded that there is a threshold velocity needed to trigger larval dispersal (Kynard et al. 2007b). Daufresne et al. (2005) deduced that drift entry is not only attributed to swimming abilities, because greater displacement rates of brown trout were observed at lower and higher velocities.

Other abiotic factors than light and current can provoke an active drift entry: Gale and Mohr (1978) interpreted the high densities of drifting larvae downstream of an acid mine drainage as escape from heavily polluted waters; and the negative correlation of drift density and suspended particular matter in the main channel of the Elbe has been attributed to active drift avoidance (Oesmann 2003).

\section{Drift control and orientation}

Pavlov's classification of larval drift modes has served as a basis for almost all the work that has been carried out on this topic (but see his review papers: Pavlov 1994 and Pavlov et al. 2008). He cites the most common drift mode as constituting passive drift: nonoriented individuals are transported downstream at the same rate as the current speed. Passive drift mode likely corresponds to accidental drift entry, typical of the early larval stages and usually observed in the dark. The opposite, active drift, logically follows a deliberate entry into the current. Here, oriented individuals move faster downstream than the current, primarily during daytime. A hybrid form, activepassive drift, is characterized by upstream oriented fish, moving downstream at lower rates than the mean current speed. This mode, originally attributed to impaired swimming ability at decreased water temperatures and during starvation (Pavlov et al. 2008), is now considered as one manifestation of negative rheoreaction; i.e. an oriented, active downstream movement (Pavlov et al. 2011).

Below, we review the evidence for active and passive drift in the literature. We suggest that recent work indicates that classification into discrete drift modes may not be the best model of what happens in the wild, and instead, we offer an alternative approach.

Passive drift

A solely passive downstream transport of larvae is mostly ascribed to a combination of poor swimming abilities with highly variable flow conditions in rivers (Corbett and Powles 1986; Gadomski and Barfoot 1998; de Graaf et al. 1999). Average current speeds in rivers often exceed swimming speeds of recently hatched larvae (Wolter and Sukhodolov 2008). Additionally, turbulent flows make maintaining position or direction of swimming extremely difficult if not impossible for many larvae (Webb and Cotel 2011), increase the energetic costs of locomotion (Liao 2007) and reduce the critical swimming velocities young fish can maintain (Lupandin 2005).

If passive transport is the norm, vertical and lateral distributions of drifting fish larvae depend on the location of upstream spawning sites (Brown and Armstrong 1985; D'Amours et al. 2001) and a subsequent exposure to hydraulic forces (e.g. average current speeds, transverse flow circulations, rheogradients, turbulent mixing; Pavlov 1994; Pavlov et al. 2008). Therefore, passively drifting individuals should become redistributed according to their body shape and buoyancy (Copp et al. 2002). They should end up in depositional habitats (e.g. groyne fields; Lechner et al. 2014a) or be concentrated in dead zones, slackwater habitats (Wolter and Sukhodolov 2008; Kopf et al. 2014) and concave riverbanks (Pavlov et al. 2008). Depending on discharge levels, hydraulic forces may concentrate young fish in areas with high current speeds, such as the thalweg (Braaten et al. 2010; Ellsworth et al. 2010a). If larvae are kept in suspension under high discharges, this may considerably increase drift distance and influence longitudinal distribution patterns (Corbett and Powles 1986).

However, a growing number of studies, documenting behavioural, sensorial and physical abilities of young fish (Garner 1999; Hogan and Mora 2005; Stoll and Beeck. 2012), refute the model of a solely passive 
drift. Specifically, it has been shown that the spatiotemporal dispersal patterns of fish larvae differ from those of virtual (Schludermann et al. 2012) and physical (Lechner et al. 2014a) passive particles, and that passive transport models overestimate drift distance by far (Braaten et al. 2012).

\section{Active drift}

The drifting free embryos and larvae of some species are well developed and are active swimmers, able to determine their location in the water column (Peňáz et al. 1992; Humphries 2005). Even at low light levels and overcritical currents, they may respond to hydraulic gradients and drift under certain conditions (Kaminskas 2011; Schludermann et al. 2012). Experiments on zebrafish larvae (Danio rerio, Cyprinidae), for instance, showed that rheoreaction is mediated by neuromasts of the lateral line, which enables young fish to sense water flows and orient in currents at night (Olszewski et al. 2012; Stewart et al. 2013).

If active transport is the norm, the spatial distribution of drifting larvae depends on deliberate swimming behaviour and the ability to locate preferred hydraulic habitat, or at least to orientate along gradients which lead to these (Robinson et al. 1998). Vertical positioning of drifting larvae may reflect an effort to avoid benthic predators and collisions with the substrate (Brown and Armstrong 1985; Gadomski and Barfoot 1998). Lateral positioning of drifting larvae, however, is thought to be a result of specific dispersal strategies; e.g., drifting near-shore to enhance the probability of being able to move into suitable habitat when coming close to it (Araujo-Lima and Oliveira 1998), or drifting offshore to accelerate transport and thereby minimize mortality (Reichard et al. 2004). The distance covered during active drifting will clearly vary depending if larvae choose to drift at low (Lechner et al. 2014b), intermediate (Schludermann et al. 2012) or high currents (Oesmann 2003) and whether they drift low or high in the water column (Kynard et al. 2007a).

\section{A continuum mode of dispersal: actipassive drift}

We argue that, aside from eggs, the early developmental stages of fish are not exclusively either passive or active drifters. On the one hand, the hydraulic forces can exceed the swimming capabilities of free embryos and larvae (Wolter and Arlinghaus 2003). On the other hand, even tiny larvae display orientation in the dark at over-critical currents and can, to a degree, regulate their dispersal (Zens 2015). Therefore, a strict separation of drift modes, as applied in the majority of studies (active: Peňáz et al. 1992; Robinson et al. 1998; Humphries 2005; Braaten et al. 2012; passive: Armstrong and Brown 1983; Harvey 1987; de Graaf et al. 1999; Wolter and Sukhodolov 2008; Ellsworth et al. 2010a; Janac et al. 2013) appears inappropriate. Although, it may appear reasonable to evaluate the ratio of active and passive components for single dispersal events along a continuum (Fig. 1), this ratio must result from the strength of hydraulic forces and species-or stage-specific capabilities (behavioural, physical). A profound knowledge of larval skills (i.e. swimming performance, orientation ability, drift behaviour) and the limiting environmental conditions is required, if one wants to assess the proportion of each component. As a theoretical model we suggest instead, that the drift of larvae, free embryos and juveniles should be referred to as an actipassive process. Provided there is detailed information on the ratio, the terms active-passivefor a predominantly controlled mode of downstream movement-and passive-active-for a primary externally vectored transport-might be used.

\section{An integrated approach to the drift of early life stages of riverine fishes}

The state of knowledge in research on the drift of early life stages of riverine fishes was reviewed, based on peer-reviewed publications between 1972 and 2014 (see Online Resource). Of the 60 publications, $89 \%$ were field studies, and of these, $85 \%$ used stationary drift nets (Fig. 2). The research was conducted in 54 rivers on 4 continents, but mostly in temperate floodplain - and upland rivers in North America and Europe (Fig. 2, Online Resource). Only $10 \%$ of these studies used hydrodynamic or mathematical models to explain or predict drift patterns. We analysed all publications using a conceptual framework of organismal movement advocated by Nathan et al. (2008) (Fig. 3). According to Nathan et al. (2008), the movement path of a focal individual results from the dynamic interplay of four basic components: 


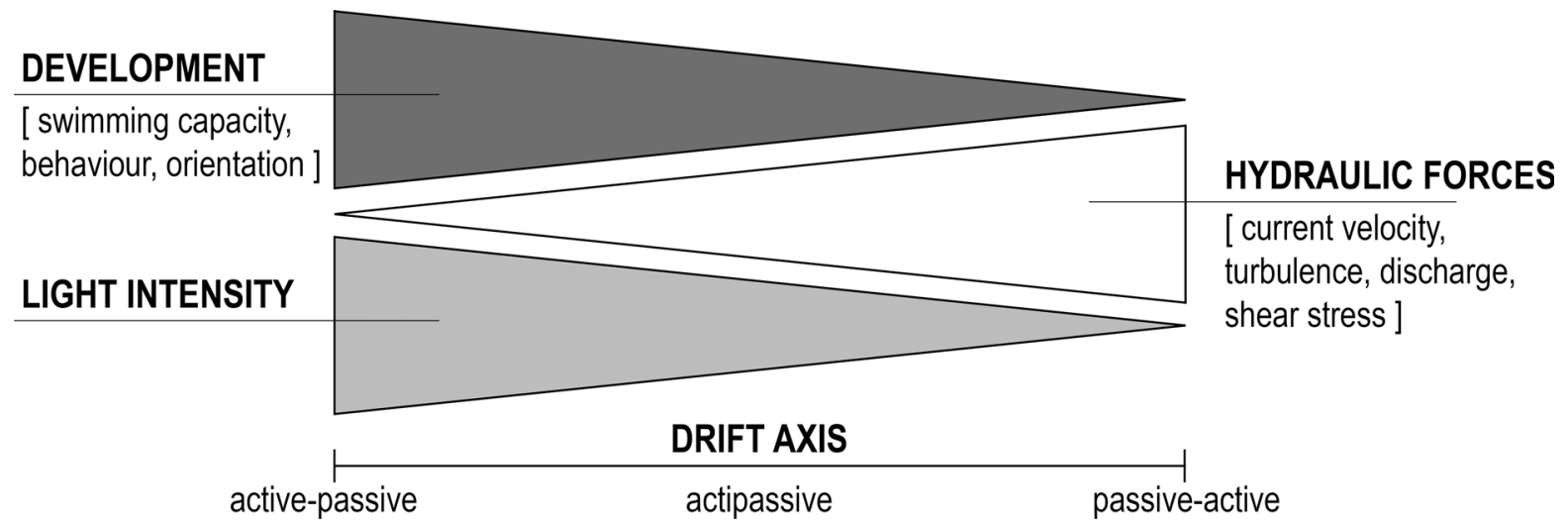

Fig. 1 Illustration of the continuum drift mode. Triangles represent the range of parameters with low values for hydraulic forces and rudimentary developmental state at the apexes
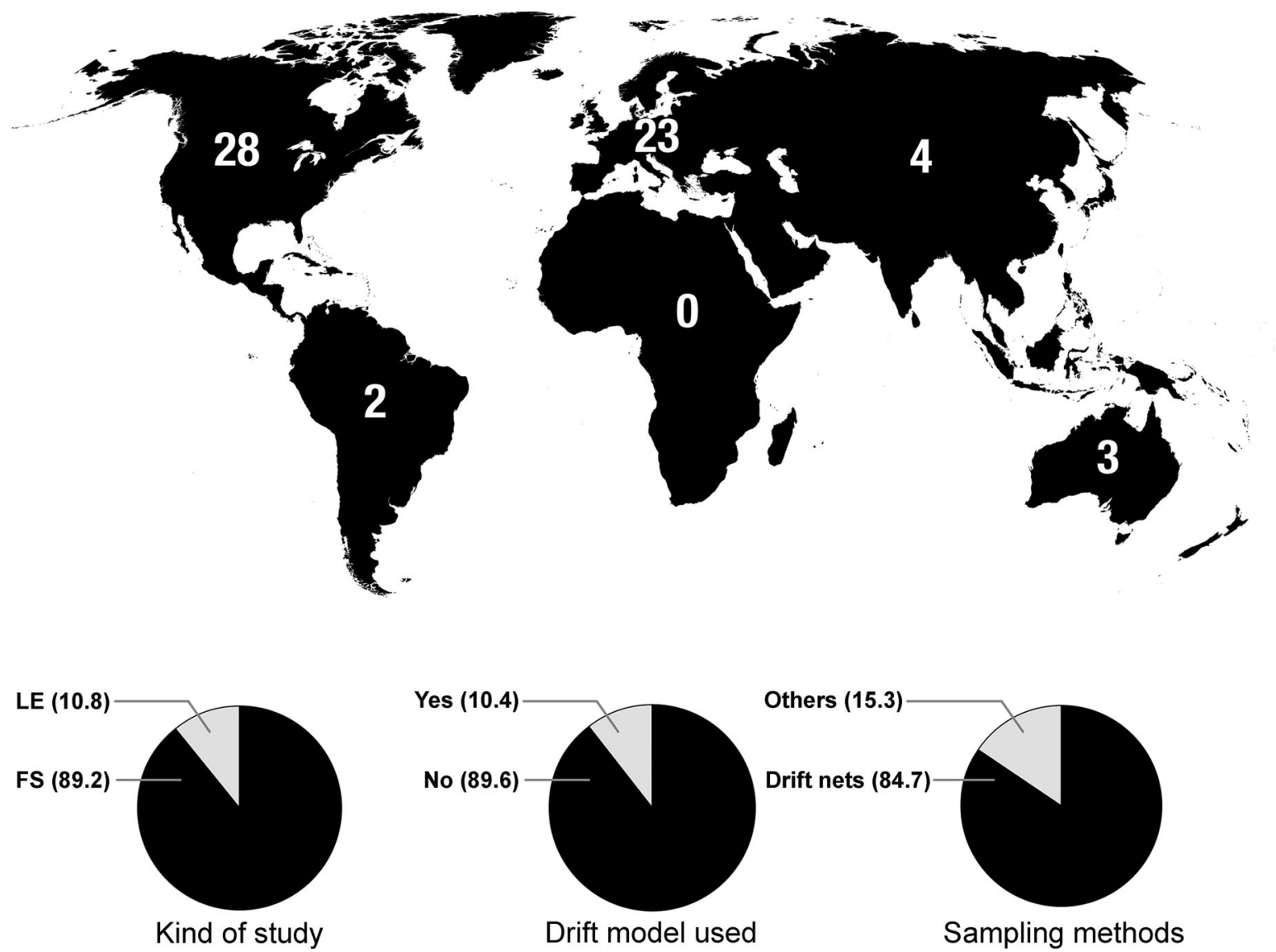

Fig. 2 Overview of the geographical distribution of the 60 analysed drift studies. The percentage of field studies (FS) and laboratory experiments (LE) as well as the frequency of drift model- and driftnet-usage is given in the pie charts below 


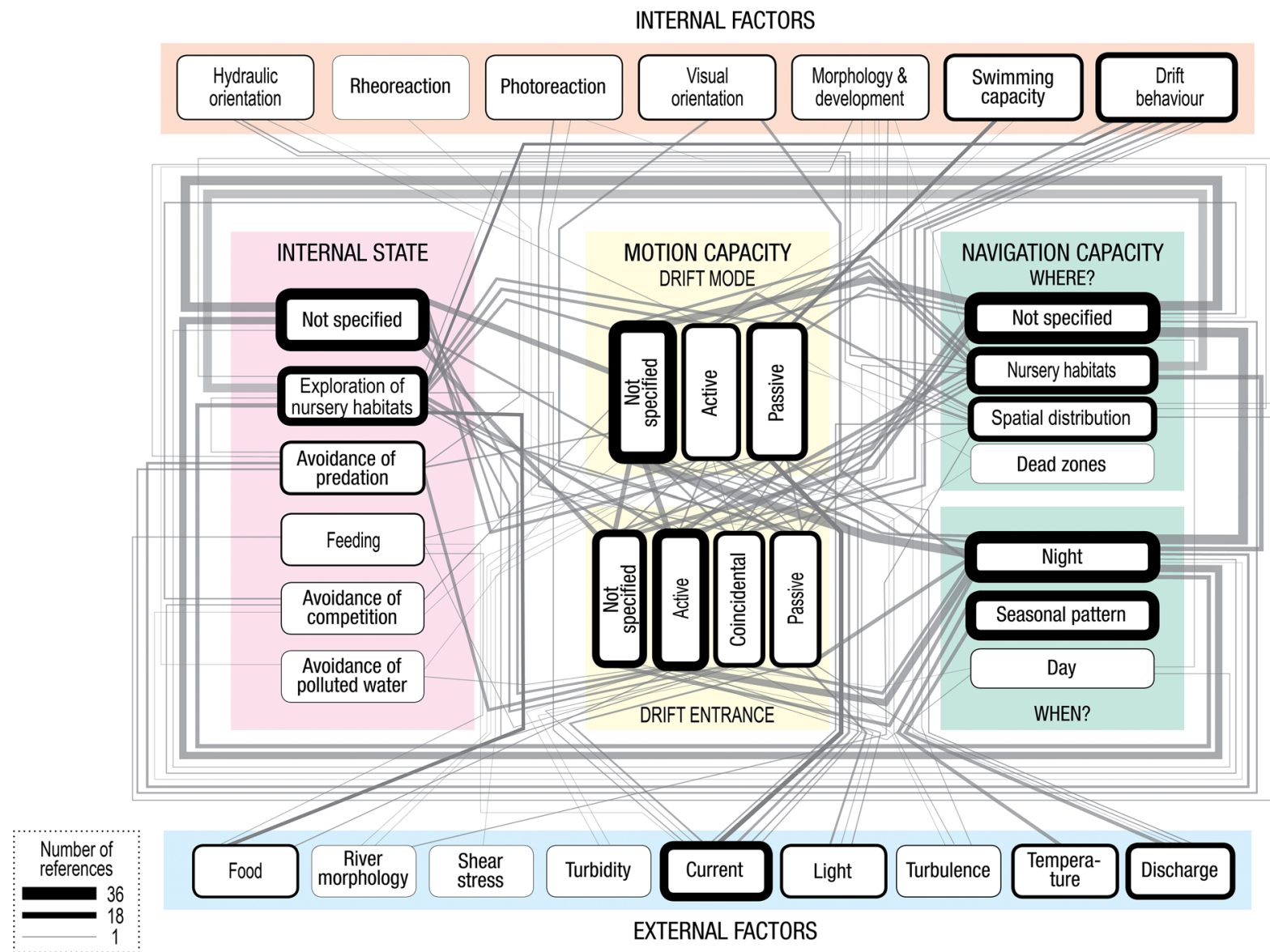

Fig. 3 Characteristics of larval fish drift, as derived from the relevant literature, are displayed on the base of a general framework for movement ecology (coloured blocks; Nathan et al. 2008). Frame- and line thickness refer to the frequency of

1. internal state- - the different motivations to move or "why do the early life stages of riverine fishes drift?";

2. navigation capacity - the orientation ability of moving organisms or "where and when do the early life stages of riverine fishes drift?";

3. motion capacity - the different modes (active, passive) of movement or "how do the early life stages of riverine fishes drift?";

4. external factors-biotic and abiotic parameters that affect why, how, where and when to drift.

But because of the field of research, we introduced a fifth component:

5. internal factors - a set of intrinsic characteristics (e.g. physiology and morphology) that influence different components of drift movement. described cases and connections. For reasons of clearness, existing links between internal and external factors are not drawn

Each publication was scrutinized for specific information associated with the above-outlined model. Information was categorized, where applicable, and displayed in framed white boxes within the five components (Fig. 3). The "not-specified" boxes refer to studies that provide no answers on why, how or where fish drift. Lines between boxes indicate cooccurrence or cause-and-effect relationships, as obtained from the literature. The thickness of frames and lines represent the relative frequency of references to a particular aspect. Both speculative and empirical conclusions-drawn by the authors themselves-on drift characteristics were included in this meta-analysis. A synopsis shows the most common categories (except "not specified") and linkages (Fig. 4). This will serve as a roadmap to discuss the current state of knowledge 


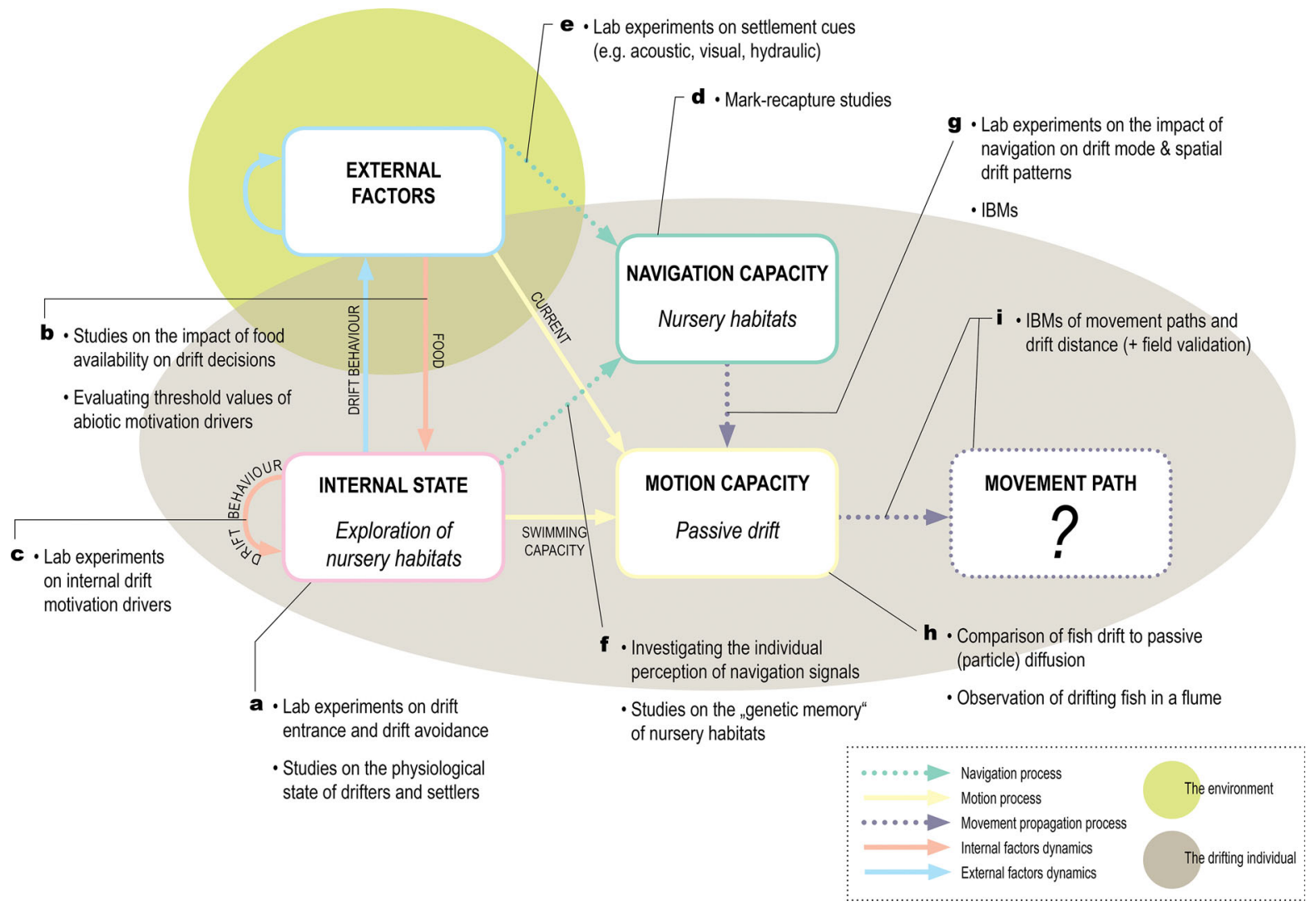

Fig. 4 Conceptual model of fish drift inspired by Nathan et al. (2008), showing the processes and relationships (indicated by arrows) between the five basic components (boxes) of dispersal. Dotted lines show knowledge gaps in the reviewed literature $(<5$ references). Black lines $(a-i)$ indicate suggested research needs for particular aspects of fish drift. Detailed information of the glossary is given in Nathan et al. (2008). Briefly: the navigation process refers to the realized navigation capacity given the

in drift research, and identify requirements for future studies. Note, the data content was adapted to accord with Nathan's framework. Therefore, drift entrance modes and temporal patterns of drift were excluded, and have already been considered in the above.

Internal State: "why do the early life stages of riverine fishes drift?"

The internal state of drifting larvae is not specified in most studies reviewed (Fig. 3). Determining the motivation for a single drift event is a challenging task. It requires the assessment of the psychological (do larva have a psyche?) and physiological state of a small fish, at any given time, driving it to fulfil a impact of the current location, internal state, and external factors on the fundamental navigation capacity of the focal individual; the motion process refers to the realized motion capacity given the impact of the current location, internal state, and external factors on the fundamental motion capacity of the focal individual; the movement propagation process refers to the realized movement produced by the motion process (optionally affected by the navigation process)

particular goal by changing its position. This is compounded by complex phenotypic and genotypic behaviour-environment interactions. Perhaps, except for amphidromous species, where the objective is to reach the sea, it is always going to be uncertain whether drift is the result of a desire to reach a destination, or to avoid a threat, such as competition, predation or poor water quality, at its current location (Nathan et al. 2008).

The perception-perhaps anthropocentric-of larvae looking for the most advantageous feeding grounds underlies many drift studies (Fig. 4). Recently hatched fish are unlikely to be aware of suitable downstream areas (but see Navigation capacity). Rather than a 'motivation' per se, the 'exploration of nursery 
habitats' may be a by-product of an active drift entrance that potentially refers to ultimate evolutionary payoffs from moving (e.g. gaining energy, dampening population fluctuations by spreading larvae over heterogeneous environments etc.). Whilst this last is hard to prove, the motivation to leave disadvantageous areas can be tested in laboratory experiments on drift entrance by controlling conditions of water quality, predation or competition (Fig. 4a). In this respect, the impact of predator kairomones on young fishes' drift entrance dynamics, as shown for invertebrates (Winkelmann et al. 2008), could be of particular interest. Investigations of the physiological state of drifting (and settling) fish may clarify whether hunger is an important driver of drift.

Specific attention should be given to external factors that stimulate or discourage young fish to move. Food availability, for example, is mentioned a common reason to leave, or look for a specific habitat (Fig. 4). To the best of our knowledge, there is no study that actually investigated food quality or quantity at the starting- or end-point of a drift event. Evaluating the threshold values of other abiotic factors (e.g. current, light), which affect the fish's internal state, will provide deeper insights into why, when and where young fish enter the flow (Fig. 4b). Furthermore, a profound understanding of an individual's motivation to drift (i.e. drift behaviour) allows more informed conclusions to be drawn on the significance of environmental conditions encountered on the way (Fig. 4): larvae of potamodromous species, for example, that search the river shorelines for suitable habitats, potentially prefer lower currents than those of anadromous species that aim for the distant ocean.

The motivation for drifting is most likely selfregulated by internal factors (Fig. 4). However, detailed knowledge on how (ontogenetic) changes in morphology, swimming capacity, orientation ability or behaviour affect the readiness to move, or assist a specific drift strategy, is required. Again, laboratory experiments appear to be the appropriate method (Fig. 4c).

\section{Navigation capacity: "where}

and when do the early life stages of riverine fishes drift?"

The drift destination is not specified in most work on dispersing fish larvae in rivers (Fig. 3). Indeed, nursery areas are frequently assumed by authors to be where larvae stop drifting (Fig. 4) but there is no sure indication for this conclusion, as most studies do not observe settlement activities (Kennedy and Vinyard 1997; Schludermann et al. 2012; Lechner et al. 2014a). Hence, an increased application of markrecapture experiments, focusing on drift exit and habitat choice along the shoreline, will provide valuable information (Fig. 4d). Using genetic and geochemical markers (see reviews by Hedgecock et al. 2007 and Thorrold et al. 2007) or trans-generational tagging approaches, offers the possibility to mark large numbers of fish larvae (Thorrold et al. 2006; Zite et al. 2014), and should be more commonly incorporated into riverine drift studies.

Almost nothing is known of the navigation ability of drifting fish and the influencing external and internal factors (Fig. 4). This kind of knowledge, however, is indispensable to understand how larvae detect and reach suitable inshore habitats and to predict spatial patterns of drift. Studies on marine species have shown that fish larvae navigate toward settlement areas by reacting to a variety of environmental stimuli (Dixson et al. 2011; Leis et al. 2011; Huijbers et al. 2012). Consequently, we encourage studies on the settlement cues for drifting fish in running waters (Fig. 4e). Those cues potentially encompass acoustic (e.g. the sound of the wave-wash) or visual (e.g. shading by vegetation) signals and hydraulic gradients (e.g. current speed, current direction, water depth) that indicate shore proximity. Given the limited observability of small fish in large rivers, the feasibility of such studies is mainly restricted to laboratory experiments.

The internal state of the individual (e.g. neurological and physiological) potentially influences the process of navigation. Studies are needed that examine the species-and stage-specific ability to sense and respond to navigation signals (Fig. 4f). Furthermore, the question arises whether fish larvae, as some birds do (Nathan et al. 2008), possess a genetically coded 'memory' guiding them towards suitable nursery areas. The long-time observation of downstream habitat use (i.e. 'nursery fidelity') by marked larvae from a known spawning ground could throw light on the matter (Fig. 4f).

In future research, the focus must shift to how individuals implement navigation decisions in the process of drifting (i.e. Motion capacity). Many 
studies ascribe the observed spatial distribution patterns (i.e. lateral and horizontal; Online Resource) of drifting fish to active navigation (i.e. active drift), but remain vague about the underlying mechanisms (Brown and Armstrong, 1985; Gadomski and Barfoot 1998; Robinson et al. 1998; Schludermann et al. 2012). Certainly, the observation of individuals in an artificial stream-channel is a potent method to correlate a variety of navigation-related cues to the drift mode under controlled conditions, thereby elucidating spatial patterns of transport (Fig. $4 \mathrm{~g}$ ). The ultimate significance of the suggestions above is debatable, as transferring laboratory results to the field has its drawbacks. A promising approach, in this respect, is the field validation of predicted spatial drift outcomes by biophysical models that incorporate larval navigation abilities recorded in the laboratory (Fig. 4g). These individual based models (IBM) are an emerging tool in oceanic research (Cowen et al. 2006; Christensen et al. 2007; Staaterman and Paris 2014), supporting the identification of potential nurseries and spawning grounds. In freshwater systems, this technique is in its infancy.

Motion capacity: "how do the early life stages of riverine fishes drift?"

Generally, the mode of transport is not specified in drift studies (Fig. 3). This is at first attributable to the common sampling method, i.e. exposing stationary nets into the current to capture autochthonous fish fry. Missing information on where larvae had started drifting, and the environmental conditions along their route, make reliable statements on the drift mode impossible. The frequent reports of passive drift caused by strong currents (Fig. 4), thus often derive from a simple comparison between values of current speed (measured at the net opening) and larval swimming performance (Corbett and Powles 1986; Gadomski and Barfoot 1998; Wolter and Sukhodolov 2008).

The eulerian observation of larval movement (using drift nets) in relation to passive particles is a promising approach for a rough identification of the drift mode (Fig. 4h). The spatio-temporal drift patterns of marked and recaptured individuals can be either compared to those of physical floats, ideally featuring some larval attributes (e.g. shape and density), or to those of virtual particles, simulated using specific tracking software on the base of hydrodynamic models (Schludermann et al. 2012; Lechner et al. 2014a).

Flume experiments have a great potential to reveal specific peculiarities of the drift mode, however, they are rarely applied (Persat and Olivier 1995; Kynard et al. 2007a; Kaminskas 2011; Pavlov et al. 2011; Zens 2015). We suggest that future work should focus on the transport mode of different species (e.g. invasive, endemic, riverine, lentic, benthic), developmental stages, ecological guilds (e.g. reproduction and current) etc. in the laboratory, where abiotic factors (i.e. current, temperature, turbidity and turbulence) are changed while observing drifting fish (Fig. 4h).

Movement path: "which way do drifting larvae take?"

So far, there is no existing knowledge on the exact route of drifting young fish in rivers (Fig. 4). The limiting factor is, again, the traditional method of collecting larva: drift net samples are point measurements, providing no information on the processes between two points. However, the instructive in situ tracking of larval movement, as demonstrated in marine studies (Huebert and Sponaugle 2009; Paris et al. 2013), is made problematic by swift currents, turbid water and the nocturnal drift activity in rivers (Kennedy and Vinyard 1997).

In our opinion, the most practicable and sophisticated way is to simulate larval movement paths with IBMs and validate the results in the field (Fig. 4i). This requires a specific understanding of navigation capacity and motion capacity. Furthermore, high resolution 3D-hydrodynamic river models are needed to predict a larva's reactions towards hydraulic gradients en route. The field validation should preferably be based upon mark-recapture studies at different spatial scales with well-understood model species (see Lechner et al. 2014a).

In order to set the spatial limits of a movement path, it might initially be useful to focus on the distance covered during a drift event. Mathematical models have been used to estimate drift distances of some sturgeon species by integrating flow velocity and empirical data on drift duration, drift mode and swimming height (Kynard et al. 2007a; Braaten et al. 2008,2012 ), but these sorts of studies are rare. There is an urgent need for research regarding the drift distance of other fishes (Fig. 4i). 
Data on the spatial characteristics (i.e. route and distance) of fish drift are important to evaluate the connectivity of key habitats (spawning-rearing) and will have implications for river management and restoration projects. Information on the average drift distance, for example, could influence the designation of protected areas downstream of known reproduction sites.

\section{Conclusion}

This review clearly shows that we are far from a general understanding of the processes and patterns of fish drift. As stated previously, the most common technique in the investigation of the drift of the young stages of fish is the deployment of stationary drift nets. This technique is unsuitable for finding answers to the pressing questions in the field that we have identified. We believe that laboratory observations and experiments are essential to elucidate the sensorial, physical and behavioural capabilities of fish larvae, which will in turn provide information on the processes involved in navigation capacity, motion capacity and internal state. The information gained will improve riverine drift models. These are a rarely-used, but powerful tool for understanding dispersal, and will shed light on movement path and/or settlement behaviour.

Increasing our understanding of the nature of the dispersal ecology of the early life stages of riverine fishes is urgently needed. The increasing human impact on rivers worldwide impinges on all aspects of the ecology of fishes, but young fish are particularly vulnerable. Implications of river channelization and flow regulation: (1) disturb localized settlement and movement in inshore areas (Braaten et al. 2012); (2) disrupt natural dispersal signals and affect drift distance (Ellsworth et al. 2010b; Usvyatsov et al. 2013); (3) increase washout-effects and catastrophic drift entrance during high water levels and navigationinduced wave wash (Bischoff and Wolter 2001; Kucera-Hirzinger et al. 2009; Schludermann et al. 2013); and (4) jeopardize drifting fish by entrainment into water abstraction sites (Carter and Reader 2000; Pavlov et al. 2008; Bracken and Lucas 2013). An integrated approach to the ecology of drifting fish in rivers will greatly contribute to effective conservation and management of riverine fish populations.
Acknowledgments Open access funding provided by University of Vienna. This work was financed by Austrian Science Fund (FWF; project MODI P22631-B17; http://www. fwf.ac.at;). J. Waldhör, A. Pivo and A. Seidel helped with the figures. Fruitful discussions with our colleagues, especially during the 39th Larval Fish Conference in Vienna, improved the manuscript enormously.

Open Access This article is distributed under the terms of the Creative Commons Attribution 4.0 International License (http:// creativecommons.org/licenses/by/4.0/), which permits unrestricted use, distribution, and reproduction in any medium, provided you give appropriate credit to the original author(s) and the source, provide a link to the Creative Commons license, and indicate if changes were made.

\section{References}

Araujo-Lima CARM, Oliveira EC (1998) Transport of larval fish in the Amazon. J Fish Biol 53:297-306. doi:10.1006/ jfbi.1998.0815

Armstrong ML, Brown AV (1983) Diel drift and feeding of channel Catfish Alevins in the Illinois River, Arkansas. Trans Am Fish Soc 112:302-307. doi:10.1577/15488659(1983)112<302:Ddafoc $>2.0$. Co; 2

Auer NA, Baker EA (2002) Duration and drift of larval lake sturgeon in the Sturgeon River, Michigan. J Appl Ichthyol 18:557-564. doi:10.1046/j.1439-0426.2002.00393.x

Bardonnet A (1993) Use of visual landmarks by young trout (Salmo-Trutta) during their diel downstream postemergence displacement in experimental channels. J Fish Biol 43:375-384. doi:10.1111/j.1095-8649.1993.tb00572.x

Bardonnet A (2001) Spawning in swift currents: implications for eggs and larvae. Archiv für Hydrobiologie Supplement 135(2-4):271-291. doi:10.1127/lr/12/2001/271

Bell KNI, Brown JA (1995) Active salinity choice and enhanced swimming endurance in 0-D-Old to 8-D-old larvae of diadromous gobies, including sicydium-punctatum (Pisces), in Dominica, West-Indies. Mar Biol 121:409-417. doi:10.1007/Bf00349450

Bischoff A, Wolter C (2001) The flood of the century on the river oder: effects on the $0+$ fish community and implications for floodplain restoration. Regul Rivers-Res Manag 17:171-190. doi:10.1002/Rrr.612

Blaxter JHS (1986) Development of sense-organs and behavior of teleost larvae with special reference to feeding and predator avoidance. Trans Am Fish Soc 115:98-114. doi:10.1577/1548-8659(1986)115<98:NLFCDO>2.0.CO;2

Borcherding J, Breukelaar AW, Winter HV, Konig U (2014) Spawning migration and larval drift of anadromous North Sea houting (Coregonus oxyrinchus) in the River IJssel, the Netherlands. Ecol Freshw Fish 23:161-170. doi:10.1111/ eff. 12058

Braaten PJ, Fuller DB, Holte LD et al (2008) Drift dynamics of larval pallid sturgeon and shovelnose sturgeon in a natural side channel of the upper Missouri River, Montana. North Am J Fish Manag 28:808-826. doi:10.1577/M06-285.1 
Braaten PJ, Fuller DB, Lott RD, Ruggles MP, Holm RJ (2010) Spatial distribution of drifting pallid sturgeon larvae in the missouri river inferred from two net designs and multiple sampling locations. North Am J Fish Manag 30:1062-1074. doi:10.1577/M09-149.1

Braaten PJ, Fuller DB, Lott RD et al (2012) An experimental test and models of drift and dispersal processes of pallid sturgeon (Scaphirhynchus albus) free embryos in the Missouri River. Environ Biol Fishes 93:377-392. doi:10.1007/ s10641-011-9925-9

Bracken FSA, Lucas MC (2013) Potential impacts of smallscale hydroelectric power generation on downstream moving lampreys. River Res Appl 29:1073-1081. doi:10. 1002/Rra.2596

Brown AV, Armstrong ML (1985) Propensity to drift downstream among various species of fish. J Freshw Ecol 3:3-17. doi:10.1080/02705060.1985.9665087

Bujold V, Cunjak RA, Dietrich JP, Courtemanche DA (2004) Drifters versus residents: assessing size and age differences in Atlantic salmon (Salmo salar) fry. Can J Fish Aquat Sci 61:273-282. doi:10.1139/F03-162

Busch WDN, Scholl RL, Hartman WL (1975) Environmental factors affecting strength of walleye (Stizostedion-Vitreum Vitreum) Year-Classes in Western Lake Erie, 1960-70. J Fish Res Board Can 32:1733-1743. doi:10.1139/f75-207

Carter KL, Reader JP (2000) Patterns of drift and power station entrainment of $0+$ fish in the River Trent, England. Fish Manag Ecol 7:447-464. doi:10.1046/j.1365-2400.2000. 00224.x

Carter JG, Lamarra VA, Ryel RJ (1986) Drift of larval fishes in the Upper Colorado River. J Freshw Ecol 3:567-577. doi:10.1080/02705060.1986.9665151

Christensen A, Daewel U, Jensen H, Mosegaard H, St John M, Schrum C (2007) Hydrodynamic backtracking of fish larvae by individual-based modelling. Mar Ecol Prog Ser 347:221-232. doi:10.3354/Meps06980

Clark AL, Pearson WD (1980) Diurnal variations in ichthyoplankton densities at Ohio River Mile 571. Trans of the Ky Acad Sci 41:116-121

Copp GH, Cellot B (1988) Structure and function of ecosystems of the french Upper-Rhone River. 51. Drift of embryonic and Larval Fishes, especially Lepomis-Gibbosus (L), in the Upper-Rhone River. J Freshw Ecol 4:419-424. doi:10. 1080/02705060.1988.9665193

Copp GH, Faulkner H, Doherty S, Watkins MS, Majecki J (2002) Diel drift behaviour of fish eggs and larvae, in particular barbel, Barbus barbus (L.), in an English chalk stream. Fish Manag Ecol 9:95-103. doi:10.1046/j.13652400.2002.00286.x

Corbett BW, Powles PM (1986) Spawning and Larva drift of sympatric walleyes and white suckers in an Ontario Stream. Trans Am Fish Soc 115:41-46. doi:10.1577/15488659(1986)115<41:Saldos >2.0.Co;2

Cowen RK, Paris CB, Srinivasan A (2006) Scaling of connectivity in marine populations. Science 311:522-527. doi:10. 1126/science.1122039

D'Amours J, Thibodeau S, Fortin R (2001) Comparison of lake sturgeon (Acipenser fulvescens), Stizostedion spp., Catostomus spp., Moxostoma spp., quillback (Carpiodes cyprinus), and mooneye (Hiodon tergisus) larval drift in
Des Prairies River, Quebec. Can J Zool-Revue Canadienne De Zoologie 79:1472-1489. doi:10.1139/cjz-79-8-1472

Daufresne M, Capra H, Gaudin P (2005) Downstream displacement of post-emergent brown trout: effects of development stage and water velocity. J Fish Biol 67:599-614. doi:10.1111/j.1095-8649.2005.00759.x

de Graaf GJ, Born AF, Uddin AMK, Huda S (1999) Larval fish movement in the River Lohajang, Tangail, Bangladesh. Fish Manag Ecol 6:109-120. doi:10.1046/j.1365-2400. 1999.00124.x

Dixson DL, Jones GP, Munday PL et al (2011) Terrestrial chemical cues help coral reef fish larvae locate settlement habitat surrounding islands. Ecol Evol. doi:10.1002/Ece3.53

Durham BW, Wilde GR (2008) Composition and abundance of drifting fish larvae in the Canadian River, Texas. J Freshw Ecol 23:273-280. doi:10.1080/02705060.2008.9664199

Ellsworth CM, Tyler TJ, VanderKooi SP (2010a) Using spatial, seasonal, and diel drift patterns of larval Lost River suckers Deltistes luxatus (Cypriniformes: catostomidae) and shortnose suckers Chasmistes brevirostris (Cypriniformes: Catostomidae) to help identify a site for a water withdrawal structure on the Williamson River, Oregon. Environ Biol Fishes 89:47-57. doi:10.1111/j.1095-8649.2010.02701.x

Ellsworth CM, Belk MC, Keleher CJ (2010b) Residence time and drift patterns of larval June sucker Chasmistes liorus in the lower Provo River as determined by otolith microstructure. J Fish Biol 77:526-537. doi:10.1007/ s10641-010-9688-8

Elouard JM, Leveque C (1977) Nycthemeral Periodicity in Drift of Insects and Fishes in Ivory-Coast Rivers. Cah Orstom Hydrobiol 11:179-183

Flecker AS, Taphorn DC, Lovell JA, Feifarek BP (1991) Drift of Characin Larvae, Bryconamericus-Deuterodonoides, during the dry season from Andean Piedmont Streams. Environ Biol Fishes 31:197-202. doi:10.1007/Bf00001020

Flore L, Keckeis H (1998) The effect of water current on foraging behaviour of the rheophilic cyprinid Chondrostoma nasus (L.) during ontogeny: evidence of a trade-off between energetic gain and swimming costs. Regul RiversRes Manag 14:141-154. doi:10.1002/(Sici)10991646(199801/02)14:1<141:Aid-Rrr492>3.3.Co;2-W

Flore L, Reckendorfer W, Keckeis H (2000) Reaction field, capture field, and search volume of $0+$ nase (Chondrostoma nasus): effects of body size and water velocity. Can J Fish Aquat Sci 57:342-350. doi:10.1139/cjfas-57-2-342

Gadomski DM, Barfoot CA (1998) Diel and distributional abundance patterns of fish embryos and larvae in the lower Columbia and Deschutes rivers. Environ Biol Fishes 51:353-368. doi:10.1023/A:1007485015830

Gale WF, Mohr HW (1978) Larval fish drift in a large river with a comparison of sampling methods. Trans Am Fish Soc 107:46-55. doi:10.1577/1548-8659(1978)107<46:Lfdial> 2.0.Co; 2

Garner P (1999) Swimming ability and differential use of velocity patches by $0+$ cyprinids. Ecol Freshw Fish 8:55-58. doi:10.1111/j.1600-0633.1999.tb00053.x

Harvey BC (1987) Susceptibility of young-of-the-year fishes to downstream displacement by flooding. Trans Am Fish Soc 116:851-855. doi:10.1577/1548-8659(1987)116<851: Soyftd $>2.0 . \mathrm{Co} ; 2$ 
Hay CH, Franti TG, Marx DB, Peters EJ, Hesse LW (2008) Relationships between larval fish drift and abiotic factors in the missouri river. J Freshwater Ecol 23:589-597

Hedgecock D, Barber PH, Edmands S (2007) Genetic approaches to measuring connectivity. Oceanography 20:70-79. doi:10.5670/oceanog. 2007.30

Hogan JD, Mora C (2005) Experimental analysis of the contribution of swimming and drifting to the displacement of reef fish larvae. Mar Biol 147:1213-1220. doi:10.1007/s00227005-0006-5

Huebert KB, Sponaugle S (2009) Observed and simulated swimming trajectories of late-stage coral reef fish larvae off the Florida Keys. Aquat Biol 7:207-216. doi:10.3354/ Ab00200

Huijbers CM, Nagelkerken I, Lossbroek PAC et al (2012) A test of the senses: fish select novel habitats by responding to multiple cues. Ecology 93:46-55. doi:10.1890/10-2236.1

Humphries P (2005) Spawning time and early life history of Murray cod, Maccullochella peelii (Mitchell) in an Australian river. Environ Biol Fishes 72:393-407. doi:10. 1007/s10641-004-2596-z

Humphries P, King AJ (2004) Drifting fish larvae in MurrayDarling Basin rivers: composition, spatial and temporal patterns and distance drifted. Canberra Workshop June 2003, p 3-4

Humphries P, Lake PS (2000) Fish larvae and the management of regulated rivers. Regul Rivers-Res Manag 16:421-432. doi:10.1002/1099-1646(200009/10)16:5<421:Aid-Rrr594> 3.0.Co;2-4

Humphries P, Richardson A, Wilson G, Ellison T (2013) River regulation and recruitment in a protracted-spawning riverine fish. Ecol Appl 23:208-225

Iguchi K, Mizuno N (1990) Diel Changes of Larval drift among amphidromous gobies in Japan, especially rhinogobiusbrunneus. J Fish Biol 37:255-264. doi:10.1111/j.10958649.1990.tb05857.x

Iguchi KI, Mizuno N (1991) Mechanisms of embryonic drift in the amphidromous goby, Rhinogobius-brunneus. Environ Biol Fish 31:295-300

Janac M, Slapansky L, Valova Z, Jurajda P (2013) Downstream drift of round goby (Neogobius melanostomus) and tubenose goby (Proterorhinus semilunaris) in their non-native area. Ecol Freshw Fish 22:430-438. doi:10.1111/Eff. 12037

Jiang W, Liu HZ, Duan ZH, Cao WX (2010) Seasonal variation in drifting eggs and larvae in the Upper Yangtze, China. Zool Sci 27:402-409. doi:10.2108/Zsj.27.402

Johnson JH, McKenna JE (2007) Diel periodicity of drift of larval fishes in tributaries of Lake Ontario. J Freshw Ecol 22:347-350. doi:10.1080/02705060.2007.9665057

Johnson JH, McKenna JE, Douglass KA (2013) Movement and feeding ecology of recently emerged steelhead in Lake Ontario tributaries. J Appl Ichthyol 29:221-225. doi:10. 1111/Jai.12032

Johnston TA (1997) Downstream movements of young-of-theyear fishes in Catamaran Brook and the Little Southwest Miramichi River, New Brunswick. J Fish Biol 51:1047-1062. doi:10.1111/j.1095-8649.1997.tb01543.x

Johnston TA, Gaboury MN, Janusz RA, Janusz LR (1995) Larval fish drift in the Valley River, Manitoba: influence of abiotic and biotic factors, and relationships with future year class strengths. Can J Fish Aquat Sci 52:2423-2431. doi:10.1139/F95-833

Jonsson N (1991) Influence of water flow, water temperature and light on fish migrations in rivers. Nord J Freshw Res 66:20-35

Jurajda P (1998) Drift of larval and juvenile fishes, especially Rhodeus sericeus and Rutilus rutilus, in the river Morava (Danube basin). Archiv Für Hydrobiol 141:231-241

Kaminskas T (2011) Downstream movement of Murray cod free-embryos and larva. Charles Sturt University, Bathurst

Keckeis H (2001) Influence of river morphology and current velocity conditions on spawning site selection of Chondrostoma nasus (L.). Arch Hydrobiol Suppl 135:341-356. doi:10.1127//r/12/2001/341

Kennedy TB, Vinyard GL (1997) Drift ecology of western catostomid larvae with emphasis on Warner suckers, Catostomus warnerensis (Teleostei). Environ Biol Fishes 49:187-195. doi:10.1023/A:1007329010680

King A, Crook DA, Koster WM, Rylah A (2005) Comparison of larval fish drift in the lower Goulburn and mid-Murray Rivers. Ecol Manag Restor 6:136-138. doi:10.1111/j. 1442-8903.2005.230-3.x

Kopf SM, Humphries P, Watts RJ (2014) Ontogeny of critical and prolonged swimming performance for the larvae of six Australian freshwater fish species. J Fish Biol 84:1820-1841. doi:10.1111/jfb.12399

Kucera-Hirzinger V, Schludermann E, Zornig H, Weissenbacher A, Schabuss M, Schiemer F (2009) Potential effects of navigation-induced wave wash on the early life history stages of riverine fish. Aquat Sci 71:94-102. doi:10. 1007/s00027-008-8110-5

Kynard B, Horgan M (2002) Ontogenetic behavior and migration of Atlantic sturgeon, Acipenser oxyrinchus oxyrinchus, and shortnose sturgeon, A-brevirostrum, with notes on social behavior. Environ Biol Fishes 63:137-150. doi:10.1023/A:1014270129729

Kynard B, Parker E (2006) Ontogenetic behaviour and dispersal of Kootenai River white sturgeon early life intervals: a laboratory study. Final Report to Idaho Department of Fish and Game, Boise

Kynard B, Parker E, Pugh D, Parker T (2007a) Use of laboratory studies to develop a dispersal model for Missouri River pallid sturgeon early life intervals. J Appl Ichthyol 23:365-374. doi:10.1111/j.1439-0426.2007.00908.x

Kynard B, Parker E, Kynard B, Parker T (2007b) Dispersal characteristics, drift distance, and wintering behaviour of young Kootenai River White Sturgeon: a laboratory study. Final Report to Idaho Department of Fish and Game, Boise

Lechner A, Keckeis H, Schludermann E et al (2014a) Shoreline configurations affect dispersal patterns of fish larvae in a large river. ICES J Mar Sci 71:930-942. doi:10.1093/ icesjms/fst 139

Lechner A, Keckeis H, Schludermann E, Humphries P, McCasker N, Tritthart M (2014b) Hydraulic forces impact larval fish drift in the free flowing section of a large European river. Ecohydrology 7:648-658. doi:10.1002/ Eco. 1386

Leis JM, Siebeck U, Dixson DL (2011) How nemo finds home: the neuroecology of dispersal and of population connectivity in larvae of marine fishes. Integr Comp Biol 51:826-843. doi:10.1093/Icb/Icr004 
Liao JC (2007) A review of fish swimming mechanics and behaviour in altered flows. Philos Trans R Soc B-Biol Sci 362:1973-1993. doi:10.1098/rstb.2007.2082

Lupandin AI (2005) Effect of flow turbulence on swimming speed of fish. Biol Bull 32:461-466. doi:10.1007/s10525005-0125-z

Maeda K, Tachihara K (2010) Diel and seasonal occurrence patterns of drifting fish larvae in the Teima Stream, Okinawa Island. Pac Sci 64:161-176

Martin FD, Paller MH (2008) Ichthyoplankton transport in relation to floodplain width and inundation and tributary creek discharge in the lower Savannah River of Georgia and South Carolina. Hydrobiologia 598:139-148. doi:10. 1007/s10750-007-9146-6

Mion JB, Stein RA, Marschall EA (1998) River discharge drives survival of larval walleye. Ecol Appl 8:88-103. doi:10. $2307 / 2641313$

Muth RT, Schmulbach JC (1984) Downstream transport of fish larvae in a shallow Prairie River. Trans Am Fish Soc 113:224-230. doi:10.1577/1548-8659(1984)113<224: Dtofli $>2.0 . \mathrm{Co} ; 2$

Nathan R, Getz WM, Revilla E et al (2008) A movement ecology paradigm for unifying organismal movement research. Proc Natl Acad Sci USA 105:19052-19059. doi:10.1073/pnas.0800375105

Northcote TG (1962) Migratory behaviour of juvenile rainbow trout, Salmo-Gairdneri, in outlet and inlet streams of Loon Lake, British-Columbia. J Fish Res Board Can 19:201-270

Oesmann S (2003) Vertical, lateral and diurnal drift patterns of fish larvae in a large lowland river, the Elbe. J Appl Ichthyol 19:284-293. doi:10.1046/j.1439-0426.2003.00503.x

Olszewski J, Haehnel M, Taguchi M, Liao JC (2012) Zebrafish larvae exhibit rheotaxis and can escape a continuous suction source using their lateral line. Plos One. doi:10.1371/ journal.pone.0036661

Paris CB, Atema J, Irisson JO, Kingsford M, Gerlach G, Guigand CM (2013) Reef odor: a wake up call for navigation in reef fish larvae. Plos One. doi:10.1371/journal.pone.0072808

Pavlov DS (1994) The downstream migration of young fishes in rivers-mechanisms and distribution. Folia Zool 43:193-208

Pavlov DS, Sbikin YN, Vashchinnikov AE, Mochek AD (1972) The effect of light intensity and water temperature on current velocities critical to fish. Vopr Ikhtiologii 12:769-778

Pavlov DS, Kuragina GN, Nezdoliy VK, Nekrasova NP, Brodskiy DA, Ersler AL (1978) Some features of the downstream migrations of Juvenile Fishes in the Volga and Kuban Rivers. J Ichthyol 17:63-374

Pavlov DS, Lupandin AI, Degtyareva NG, Dedov SM (1995) The role of turbulence in the formation of fish larvae distribution patterns in wide and narrow water streams. Dokl Akad Nauk SSSR 341:842-845

Pavlov DS, Mikheev VN, Lupandin AI, Skorobogatov MA (2008) Ecological and behavioural influences on juvenile fish migrations in regulated rivers: a review of experimental and field studies. Hydrobiologia 609:125-138. doi:10.1007/s10750-008-9396-y

Pavlov DS, Kostin VV, Zvezdin AO (2011) Patterns of movements of fish with negative type of rheoreaction. J Ichthyol 51:536-542. doi:10.1134/S0032945211040138
Peňáz M, Roux AL, Jurajda P, Olivier JM (1992) Drift of larval and juvenile fishes in a bypassed floodplain of the upper river Rhone, France. Folia Zool 41:281-288

Persat H, Olivier JM (1995) The first displacements in the early stages of Chondrostoma nasus under experimental conditions. Folia Zool 44:43-50

Reeves KS, Galat DL (2010) Do larval fishes exhibit diel drift patterns in a large, turbid river? J Appl Ichthyol 26:571-577. doi:10.1111/j.1439-0426.2010.01481.x

Reichard M, Jurajda P (2004) The effects of elevated river discharge on the downstream drift of young-of-the-year cyprinid fishes. J Freshw Ecol 19:465-471. doi:10.1080/ 02705060.2004.9664921

Reichard M, Jurajda P (2007) Seasonal dynamics and age structure of drifting cyprinid fishes: an interspecific comparison. Ecol Freshw Fish 16:482-492. doi:10.1111/j. 1600-0633.2007.00229.x

Reichard M, Jurajda P, Vaclavik R (2001) Drift of larval and juvenile fishes: a comparison between small and large lowland rivers. Archiv Für Hydrobiol-Suppl 135(24):373-389. doi:10.1127//r/12/2001/373

Reichard M, Jurajda P, Ondrackova M (2002a) The effect of light intensity on the drift of young-of-the-year cyprinid fishes. J Fish Biol 61:1063-1066. doi:10.1006/jfbi.2002. 2116

Reichard M, Jurajda P, Ondrackova M (2002b) Interannual variability in seasonal dynamics and species composition of drifting young-of-the-year fishes in two European lowland rivers. J Fish Biol 60:87-101. doi:10.1006/jfbi.2001. 1813

Reichard M, Jurajda P, Smith C (2004) Spatial distribution of drifting cyprinid fishes in a shallow lowland river. Archiv Für Hydrobiologie 159:395-407. doi:10.1127/0003-9136/ 2004/0159-0395

Roberts JH, Angermeier PL, Hallerman EM (2013) Distance, dams and drift: what structures populations of an endangered, benthic stream fish? Freshw Biol 58:2050-2064. doi:10.1111/Fwb.12190

Robinson AT, Clarkson RW, Forrest RE (1998) Dispersal of larval fishes in a regulated river tributary. Trans Am Fish Soc 127:772-786. doi:10.1577/1548-8659(1998)127<0772: Dolfia $>2.0 . \mathrm{Co} ; 2$

Roussel JM, Bardonnet A (1999) Ontogeny of diel pattern of stream-margin habitat use by emerging brown trout, Salmo trutta, in experimental channels: influence of food and predator presence. Environ Biol Fishes 56:253-262. doi:10.1023/A:1007504402613

Schiemer F, Keckeis H, Reckendorfer W, Winkler G (2001) The "inshore retention concept" and its significance for large rivers. Arch Hydrobiol (Suppl.) (Large Rivers) 135:509-516

Schiemer F, Keckeis H, Kamler E (2003) The early life history stages of riverine fish: ecophysiological and environmental bottlenecks. Comp Biochem Physiol Part A 133:439-449. doi:10.1016/S1095-6433(02)00246-5

Schludermann E, Tritthart M, Humphries P, Keckeis H (2012) Dispersal and retention of larval fish in a potential nursery habitat of a large temperate river: an experimental study. Can J Fish Aquat Sci 69:1302-1315. doi:10.1139/F2012-061

Schludermann E, Liedermann M, Hoyer H, Tritthart M, Habersack H, Keckeis H (2013) Effects of vessel-induced 
waves on the YOY-fish assemblage at two different habitat types in the main stem of a large river (Danube, Austria). Hydrobiologia 729:3-15. doi:10.1007/s10750-013-1680-9

Schmutz S, Jungwirth M (1999) Fish as indicators of large river connectivity: the Danube and its tributaries. Archiv Für Hydrobiol 115(3):329-348. doi:10.1127/lr/11/1999/329

Shepherd WC, Mills EL (1996) Diel feeding, daily food intake, and Daphnia consumption by age- 0 gizzard shad in Oneida Lake, New York. Trans Am Fish Soc 125:411-421. doi:10. 1577/1548-8659(1996)125<0411:Dfdfia >2.3.Co;2

Somarakis S, Maraveya E, Tsimenides N (2000) Multispecies ichthyoplankton associations in epipelagic species: is there any intrinsic adaptive function? Belg J Zool 130:129-133

Sonny D, Jorry S, Watriez X, Philippart JC (2006) Inter-annual and diel patterns of the drift of cyprinid fishes in a small tributary of the Meuse River, Belgium. Folia Zool 55:75-85

Staaterman E, Paris CB (2014) Modelling larval fish navigation: the way forward. ICES J Mar Sci 71:918-924. doi:10.1093/ icesjms/fst 103

Stewart WJ, Cardenas GS, McHenry MJ (2013) Zebrafish larvae evade predators by sensing water flow. J Exp Biol 216:388-398. doi:10.1242/Jeb.072751

Stoll S, Beeck P (2012) Larval fish in troubled waters - is the behavioural response of larval fish to hydrodynamic impacts active or passive? Can J Fish Aquat Sci 69:1576-1584. doi:10.1139/F2012-086

Thorrold SR, Jones GP, Planes S, Hare JA (2006) Transgenerational marking of embryonic otoliths in marine fishes using barium stable isotopes. Can J Fish Aquat Sci 63:1193-1197. doi:10.1139/F06-048

Thorrold SR, Zacherl DC, Levin LA (2007) Population connectivity and larval dispersal using geochemical signatures in calcified structures. Oceanography 20:80-89. doi:10. 5670/oceanog.2007.31

Tonkin Z, King A, Mahoney J (2007) Testing a modification to a standard passive drift net to capture drifting ichthyofauna. Fish Manag Ecol 14:299-301. doi:10.1111/j.1365-2400. 2007.00558.x

Usvyatsov S, Picka J, Taylor A, Watmough J, Litvak MK (2013) Timing and extent of drift of shortnose sturgeon larvae in the Saint John River, New Brunswick, Canada. Trans Am Fish Soc 142:717-730. doi:10.1080/00028487.2012. 760484
Wanzenböck J, Schiemer F (1989) Prey detection in cyprinids during early development. Can J Fish Aquat Sci 46:995-1001. doi:10.1139/f89-129

Webb PW, Cotel AJ (2011) Assessing possible effects of fishculture systems on fish swimming: the role of stability in turbulent flows. Fish Physiol Biochem 37:297-305. doi:10. 1007/s10695-011-9497-9

White JL, Harvey BC (2003) Basin-scale patterns in the drift of embryonic and larval fishes and lamprey ammocoetes in two coastal rivers. Environ Biol Fishes 67:369-378. doi:10.1023/A:1025891216345

Widmer AM, Fluder JJ, Kehmeier JW, Medley CN, Valdez RA (2012) Drift and retention of pelagic spawning minnow eggs in a regulated river. River Res Appl 28:192-203. doi:10.1002/Rra.1454

Winkelmann C, Petzoldt T, Koop JHE, Matthaei CD, Benndorf J (2008) Benthivorous fish reduce stream invertebrate drift in a large-scale field experiment. Aquat Ecol 42:483-493. doi:10.1007/s10452-007-9101-7

Wolter C, Arlinghaus R (2003) Navigation impacts on freshwater fish assemblages: the ecological relevance of swimming performance. Rev Fish Biol Fish 13:63-89. doi:10.1023/A:1026350223459

Wolter C, Sukhodolov A (2008) Random displacement versus habitat choice of fish larvae in rivers. River Res Appl 24:661-672. doi:10.1002/Rra.1146

Wootton RJ (1998) Ecology of teleost fishes (fish and fisheries), vol 24. Kluwer Academic Publishers, Dordrecht

Zens B (2015) Linking behaviour and hydraulics: rheoreaction and movement patternsof early stages of C. nasus under different flow conditions. MSc, University of Vienna

Zite A, Irrgeher J, Cervicek M et al (2014) Individual-specific transgenerational marking of common carp, Cyprinus carpio L., using Sr-86/Sr-84 double spikes. Mar Freshw Res 65:978-986. doi:10.1071/Mf13235

Zitek A, Schmutz S, Unfer G, Ploner A (2004a) Fish drift in a Danube sidearm-system: i. site-, inter- and intraspecific patterns. J Fish Biol 65:1319-1338. doi:10.1111/j.10958649.2004.00533.x

Zitek A, Schmutz S, Ploner A (2004b) Fish drift in a Danube sidearm-system: II. seasonal and diurnal patterns. J Fish Biol 65:1339-1357. doi:10.1111/j.1095-8649.2004.00534.x 